\title{
Sex-specific interaction of body condition and asymmetry in carabids in distinct urbanisation stages
}

\author{
Z. Elek ${ }^{1,2,4}$, G. L. Lövei ${ }^{1}$ and M. Bátki ${ }^{3}$ \\ IDepartment of Agroecology, Aarhus University, Flakkebjerg Research Centre, Forsoegsvej 1, DK-4200 Slagelse, \\ Denmark \\ 2MTA-ELTE-MTM Ecology Research Group, Biological Institute, Eötvös Loránd University, Pázmány Péter sétány 1C, \\ H-1117 Budapest, Hungary \\ ${ }^{3}$ Eötvös Loránd University, Department of Systematic Zoology and Ecology, Pázmány Péter sétány 1C, \\ H-1117 Budapest, Hungary \\ ${ }^{4}$ Corresponding author. Phone:+36305874787(mobile),E-mail: zoltan.elek2@gmail.com
}

Keywords: Body condition, Developmental homeostasis, Fluctuating asymmetry, Ground beetles, Urbanisation.

\begin{abstract}
Physiological condition of an animal is flexible and can quickly change in relation to the quality of its environment. This makes it potentially suitable as an estimator of environmental stress. We studied the condition in three predatory ground beetles, Carabus nemoralis, Nebria brevicollis and Pterostichus melanarius along an urbanisation gradient (forest-suburban area - forest fragments in urban park) in Sorø, Denmark to test whether urbanisation-related stress is reflected in body condition. We also considered the interaction between condition and the true asymmetry using a local polynomial regression model. Females showed consistently better condition than males in all studied species. The condition indices in C. nemoralis and $N$. brevicollis were higher in the urban habitats than the other sites, while P. melanarius showed better condition in the suburban forest fragments than the forest or urban habitats. A significant negative correlation was found between condition and asymmetry for $C$. nemoralis and $N$. brevicollis in the suburban as well as urban forest fragments. This indicates a complex interaction between tolerance limits, feeding conditions and stress levels during advancing urbanisation, emphasising the importance of using multiple criteria for assessing its impact on biodiversity.
\end{abstract}

Abbreviations: FA - Fluctuating Asymmetry; GLM - General Linear Model.

\section{Introduction}

Urbanisation is one of the important human activities transforming our environment (Pickett et al. 2001). Urban areas are resource-enriched, spatially heterogeneous and temporally dynamic, often substantially different from the original, natural conditions of the area now occupied by the city (McIntyre et al. 2001). The ecological impacts of urbanisation arise from habitat alteration, the loss of certain (original) habitat types, and the creation of novel and/or ephemeral habitats, with consequent changes in species composition (Gaston et al. 2005). This includes an increase in generalist or alien species (McKinney 2001, Pickett et al. 2010), leading to biological homogenisation (McKinney and Lockwood 1999).

Modified urban landscapes could result in increased habitat diversity, creating higher species richness than in the forest sites (Eversham et al. 1996, Magura et al. 2004, Elek and Lövei 2005, 2007). Habitat specialist species are more affected by urbanisation than generalists, and their abundance and species richness usually declines as urbanisation advances (Magura et al. 2004, 2010a, Elek and Lövei 2005, 2007).

The main concern remains that urbanisation degrades environmental conditions, and this may have negative consequences for environmental quality (Magura et al. 2010a). As today more than half of humanity lives in urban areas
(UN 2006), the quality of urban environment is of an increasingly important concern. The urban environment provides several ecosystem services (Bolund and Hunhammar 1999), with tangible benefits for humans. Thus, the sooner we realise potential negative change in urban conditions, the better chances we have to mitigate them. Many urbanisation studies have aimed at the species/assemblage level (Niemelä and Kotze 2009), mainly for its intuitive simplicity. This level, however, has its own time constraints: species disappearance is not registered until all individuals die, and the appearance of later-emerging adults can further delay the response to an unfavourable environmental change. Organisms react to conditions in their habitats faster at lower organisational levels, including behavioural or physiological ones. These parameters seem promising to detect less drastic effects than population extinction (Janin et al. 2011). One such potentially useful measure reflects particular changes in the developmental homeostatis of individuals which is considered an integrative response, reflecting environmental stress over the course of individual development (Parsons 1992) and which, in invertebrates, often spans several months. These effects can be captured by analysing deviations from perfect symmetry.

At the individual level, changes in body condition could also be used to characterise habitat quality. This could even be a more flexible signal, as condition indices provide a snap- 
Table 1. Comparison of the physiological condition (characterised by the residual index) of three common ground beetle species by site or sex. Numbers are means \pm s.d. The number of individuals measured are in parentheses.Significance symbols: ${ }^{* * *} *_{-} 0.000, *^{*} *_{-} 0.001, *_{-} 0.01,{ }^{‘}-0.1$

\begin{tabular}{|c|c|c|c|c|}
\hline \multirow[t]{2}{*}{ Species } & \multicolumn{3}{|c|}{ Condition index } & \multirow[t]{2}{*}{ Comparison } \\
\hline & Forest & Suburban & Urban & \\
\hline Carabus nemoralis & $\begin{array}{l}-6.93 \pm 89.34 \\
(30)\end{array}$ & $\begin{array}{l}-13.52 \pm 90.48 \\
(64)\end{array}$ & $\begin{array}{l}25.55 \pm 91.6 \\
(42)\end{array}$ & $\mathrm{U}>\mathrm{S}^{*} ; \mathrm{U}>\mathrm{F}^{\prime}$ \\
\hline Nebria brevicollis & $\begin{array}{l}-0.53 \pm 10.22 \\
(38)\end{array}$ & $\begin{array}{l}-6.56 \pm 14.73 \\
(29)\end{array}$ & $\begin{array}{l}2.48 \pm 14.1 \\
(85)\end{array}$ & $\mathrm{U}>\mathrm{S} * *$ \\
\hline \multirow[t]{2}{*}{ Pterostichus melanarius } & $\begin{array}{l}2.27 \pm 21.6 \\
(77)\end{array}$ & $\begin{array}{l}20.68 \pm 31.16 \\
(27)\end{array}$ & $\begin{array}{l}-10.19 \pm 23.8 \\
(72)\end{array}$ & $\begin{array}{c}\mathrm{S}>\mathrm{F}^{* *}, \mathrm{~F}>\mathrm{U}^{* *} \\
\mathrm{~S}>\mathrm{U}^{* * *}\end{array}$ \\
\hline & & Female & Male & \\
\hline Carabus nemoralis & & $\begin{array}{l}23.41 \pm 102.22 \\
(77)\end{array}$ & $\begin{array}{l}-30.55 \pm 64.4 \\
(59)\end{array}$ & $\mathrm{F}>\mathrm{M} * * *$ \\
\hline Nebria brevicollis & & $\begin{array}{l}1.19 \pm 13.63 \\
(138)\end{array}$ & $\begin{array}{l}-11.78 \pm 7.3 \\
(14)\end{array}$ & $\mathrm{F}>\mathrm{M} * * *$ \\
\hline Pterostichus melanarius & & $\begin{array}{l}4.28 \pm 30.65 \\
(78)\end{array}$ & $\begin{array}{l}-3.41 \pm 21.6 \\
(98)\end{array}$ & n.s. \\
\hline
\end{tabular}

shot about the physiological state of an individual, and body condition could indicate recent foraging success (Marshall et al. 1999, Ball et al. 2015), that is influenced by changes in resource availability or environmental stress.

We have evidence that urbanisation changes habitat condition suitability for invertebrates, including ground beetles (Elek and Lövei 2007, Magura et al. 2010b), and spiders (Magura et al. 2010a), suggesting the higher diversity of forest specialists in the rural forest than in the more urbanised habitats, and resulting a remarkable difference in the species composition of isopods among the urbanisation stages (Vilisics et al. 2007). Using material collected in the Danglobe Project (Elek and Lövei 2005), we tested whether such changes are reflected in body condition for ground beetles' individuals.

We have evidence that urbanisation changes habitat condition suitability for invertebrates, including ground beetles (Magura et al. 2010b), and spiders (Magura et al. 2010a), where the diversity of forest specialist is higher in the forest than in the more urbanised habitats,) and isopods, where the species composition were different among the urbanisation stages (Vilisics et al. 2007). Using material collected in the Danglobe Project (Elek and Lövei 2005), we tested whether such changes are reflected in body condition.

We hypothesised that as urbanisation progresses, conditions for ground beetles would gradually deteriorate, and this would be reflected in body condition that is expected to gradually decrease as urbanisation progresses. We assumed a sexspecific reaction to the same factors, assuming that females would be more sensitive than males, due to their higher energy needs related to reproduction, thus they are about to maximize their energy resevoirs by building fat bodies. Therefore we expect that the females have better condition than males, though both of them would respond negatively to urbanisation (i.e., show lower condition in more urbanised habitats, than in the forest). Further, we examined if the level of fluctuating asymmetry influences body condition in a sex specific way, hence we suppose that the condition will decrease as the urbanisation progresses, this relationship will be stronger for females than males.

Our results indicate that females indeed were more sensitive than males to changes caused by urbanisation. Body condition in itself did not change as hypothesised, but individuals with higher level of asymmetry had worse condition in urban and suburban forest fragments than in the original forest.

\section{Material and methods}

\subsection{Sampling area and sampling design}

Our study area was in and around the town of Sorø, a regional centre about $80 \mathrm{~km}$ west of Copenhagen, on the island of Zealand. Originally the whole region was covered by a mixed, beech (Fagus sylvatica)-dominated forest. This forest was gradually altered as the town of Sorø developed, from the Middle Ages until today. We identified three stages of urbanisation, to form an urbanisation gradient, representing forest, suburban and urban situations, according to the Globenet protocol (Niemelä et al. 2000). The three stages were each represented by areas of at least 6 ha, and had a common origin. The forest area was part of the original forest, today a lightly thinned near-continuous forest, ca. $3 \mathrm{~km}$ west of the town centre. The suburban area was under forestry management, lying at the north-eastern edge of the town, bordered on one side by the town's suburbia, and on the other, an old ditch, a dirt road, and more forest. The built-up surface was approximately $20 \%$, and the understory indicated nitrogen-rich soil (plenty of nettle, Urtica dioica). The urban forest fragments were in the Sorø Akademi Park complex. This park is 12 ha in size, lies near the centre of the town, and apart from the buildings of a school complex and a church, contains numerous, small fragments with large beech trees, originating from the old forest. The management regime is "soft": there are only gravel paths, and the mown grass, litter and cut branches are returned to the understory of the forested patches. The builtup area was about $40 \%$. 
Traps were set up according to the Globenet protocol, and were operated every second fortnightly period (Sapia et al. 2006) between the end of April to mid-October, 2005; the total sampling effort was 1440 trap-weeks (120 traps $\times 12$ weeks). For identification, keys by Lindroth $(1985,1986)$ and Hůrka (1996) were used. Further details about the sampling design are in Elek and Lövei $(2005,2007)$. Beetles were kept at $-20^{\circ} \mathrm{C}$ before analysis. Three predators, Carabus nemoralis Müller 1764, Nebria brevicollis (F. 1792), and Pterostichus melanarius (Illiger 1783) were selected as these were species that were present in reasonable numbers at all urbanisation stages.

For evaluation, we selected individual beetles ad hoc from the catch in April-June, 2005. Our sample included 136 (out of the 155 three-month total) individuals of $C$. nemoralis (59 males, 77 females); 152 (out of the 400) individuals of $N$. brevicollis (14 males, 138 females) and 176 (out of the 356) individuals of $P$. melanarius (98 males, 78 females). Before measurements were taken, beetles were thawed, and individually placed into a standard, horizontal position using a plastic gauge in a plastic Petri dish filled with small (diameter 0.08 $\mathrm{mm})$ glass beads. They were photographed under a stereomicroscope (Nikon SMZ 800, 10×1-6.3) mounted with a digital camera (Nikon Coolpix 4500), using identical aperture and exposure; two exposures were made at maximum resolution $(2,272 \times 1,704$ pixels, in JPEG format). These digital photos were used to measure the studied morphological traits, with the assistance of the software ImageJ (Rasband 2003) with a precision of $0.001 \mathrm{~mm}$.

\subsection{Data analysis}

To characterise body condition, we used the residual index (Gould 1975), where the body mass is regressed on body size, and the residuals provide an estimate of condition (e.g., Jakob et al. 1996). For this index, the elytron length was used as proxy for body size (Lagisz 2008, Knapp and Knappová 2013). The length of the right elytron was measured with a precision $0.001 \mathrm{~mm}$. The body mass was measured using an electronic balance, to a precision of $0.1 \mathrm{mg}$. Two independent measurements were taken for every trait. Data on traits showing real fluctuating asymmetry (FA, Palmer 1994) were considered for testings the condition-asymmetry relationship based on previous studies (Elek et al. submitted). We calculated a size corrected and unsigned FA index $(\mathrm{FA}=|\mathrm{R}-\mathrm{L}|$ mean $[(\mathrm{R}+\mathrm{L}) / 2])$ as suggested by Palmer (1994), where the unsigned difference is divided by the sample mean of the average trait size ( $\mathrm{R}$ - the length of right side, while $\mathrm{L}$ denotes the length left side of a morphological traits ). We calculated a linear regression of the body mass on body size, separately for each species and sex. The residual values from the model output were compared by general linear models among the sites and sexes.

We tested differences in condition (residual index values as a response variable) by a general linear model (GLM) with the habitats and gender as fixed factors and Gaussian error structure. The differences among the levels of the tested factors (habitat type and gender) were evaluated by multiple comparisons (with Tukey computed contrast matrices for several
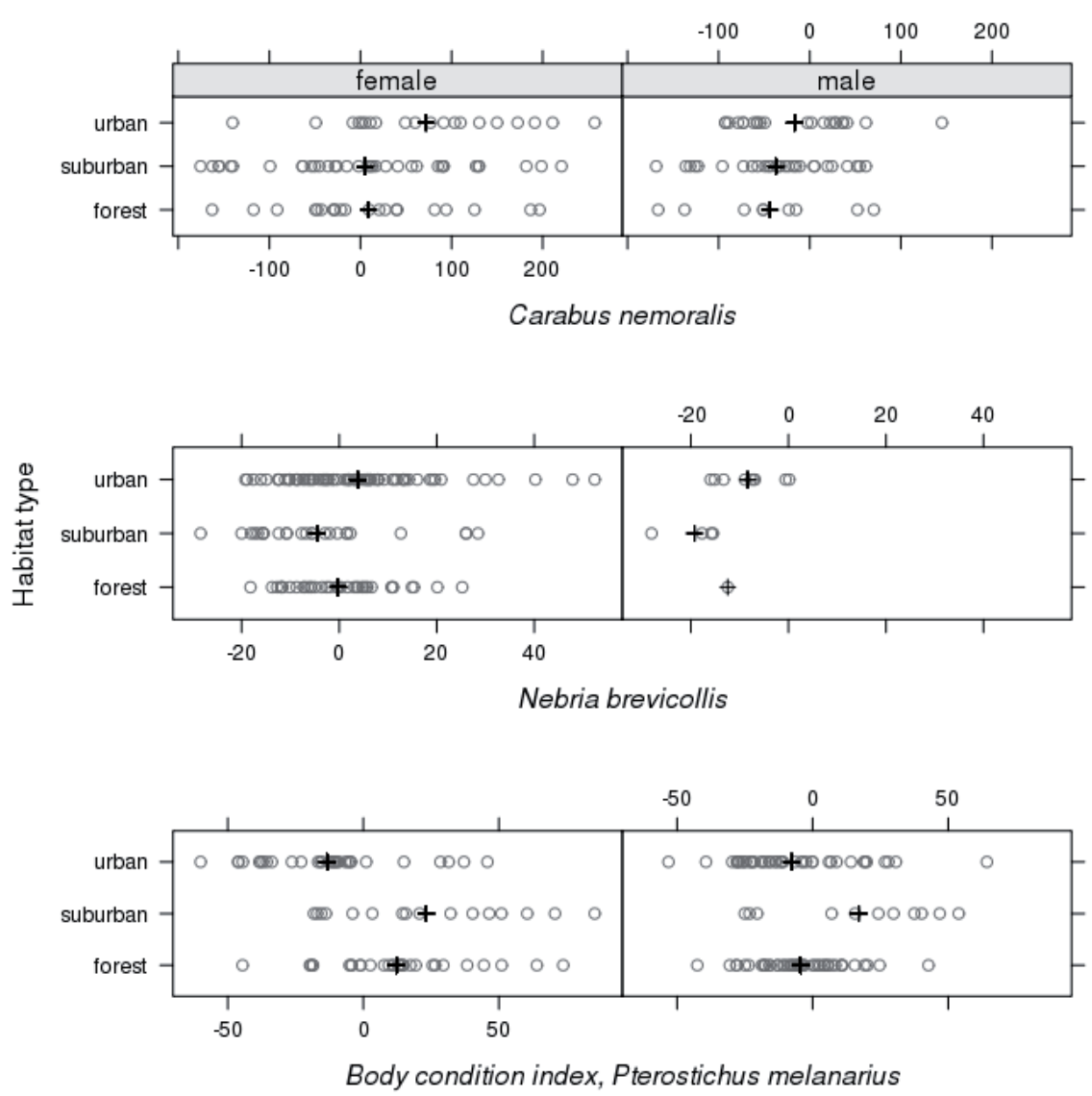

Figure 1. Distribution of condition indices in males and females of three carabid species along the urbanisatoin gradient in Sorø, Denmark, 2005. The crosses denote the arithmetic mean of the condition index. 
multiple comparisons procedures). We regressed the condition index on FA values using local polynomial regression models (loess) per habitat types and genders (Cleveland et al. 1992) for the species where the models showed significant effects. The loess is a procedure to fit a regression surface to data through multivariate smoothing. The dependent variable is smoothed as the function of the independent variable(s) in a similar fashion as the moving average is computed in the time series analysis. The fundamental form is $y_{i}=g\left(x_{i}\right)+\varepsilon_{i}$, where the " $y$ " is the dependent, the " $x$ " is the independent variable, $\varepsilon_{i}$ is the error term and the " $g$ " is the smoothing function of the independent variables. With local fitting, we can estimate a wider class of smoothing functions, than we can except from any specific parametric class of functions (Cleveland and Devlin 1988). The analyses were carried out in R 2.11.1 (R Development Core Team 2010) using the packages multcomp (Hothron et al. 2008), lattice (Deepayan 2008) and agricolae (Mendiburu 2010).

\section{Results}

\subsection{Condition index in relation to urbanisation stage}

Body condition of the three species reacted differently to urbanisation. C.nemoralis had the best condition in the urban forest fragments, demonstrating a significantly higher index here than in either of the other two habitats (Fig. 1, Table 1). N.brevicollis also had the highest index in the urban forest fragment, somewhat (but not significantly) lower in the forest, and significantly lower in the suburban habitat (Fig.
1, Table 1). P.melanarius showed better condition in the suburban forest fragments than in either the urban or forest habitats; forest beetles were also in better condition than urban ones (Fig. 1, Table 1).

\subsection{Condition index in females vs. males}

Females of $C$. nemoralis and $N$. brevicollis showed significantly better condition than males did (Fig. 1, Table 1). Urban females of $C$. nemoralis were in better condition than males. In N. brevicollis, both urban and forest females were in better condition than males from the corresponding sites, but the overall difference, while in the same direction, was not significant (Fig. 1, Table 1).

\subsection{Interaction between fluctuating asymmetry and condition}

There generally was a negative relationship between the FA values and the condition index. In C. nemoralis, the slope of the relationship was steeper in the more urbanised habitats (suburban forest fragments and urban park) than in the forest (Fig. 2). Both sexes showed a similar negative relationship (Fig. 2). In N. brevicollis, the slope was less steep in the forest than the other two habitats (Fig. 3). Females with higher FA had worse body condition than males in both suburban and urban forest fragments (Fig. 3). No consistent pattern was found between FA and condition for P. melanarius for either habitat types or sex.
Figure 2. The relationship between fluctuating asymmetry and body condition in C. nemoralis along the urbanisation gradient and between in males and females in Sorø, Denmark, 2005. The line is the locally weighted regression between the two variables, with lambda $=1$, alpha $=0.9$.

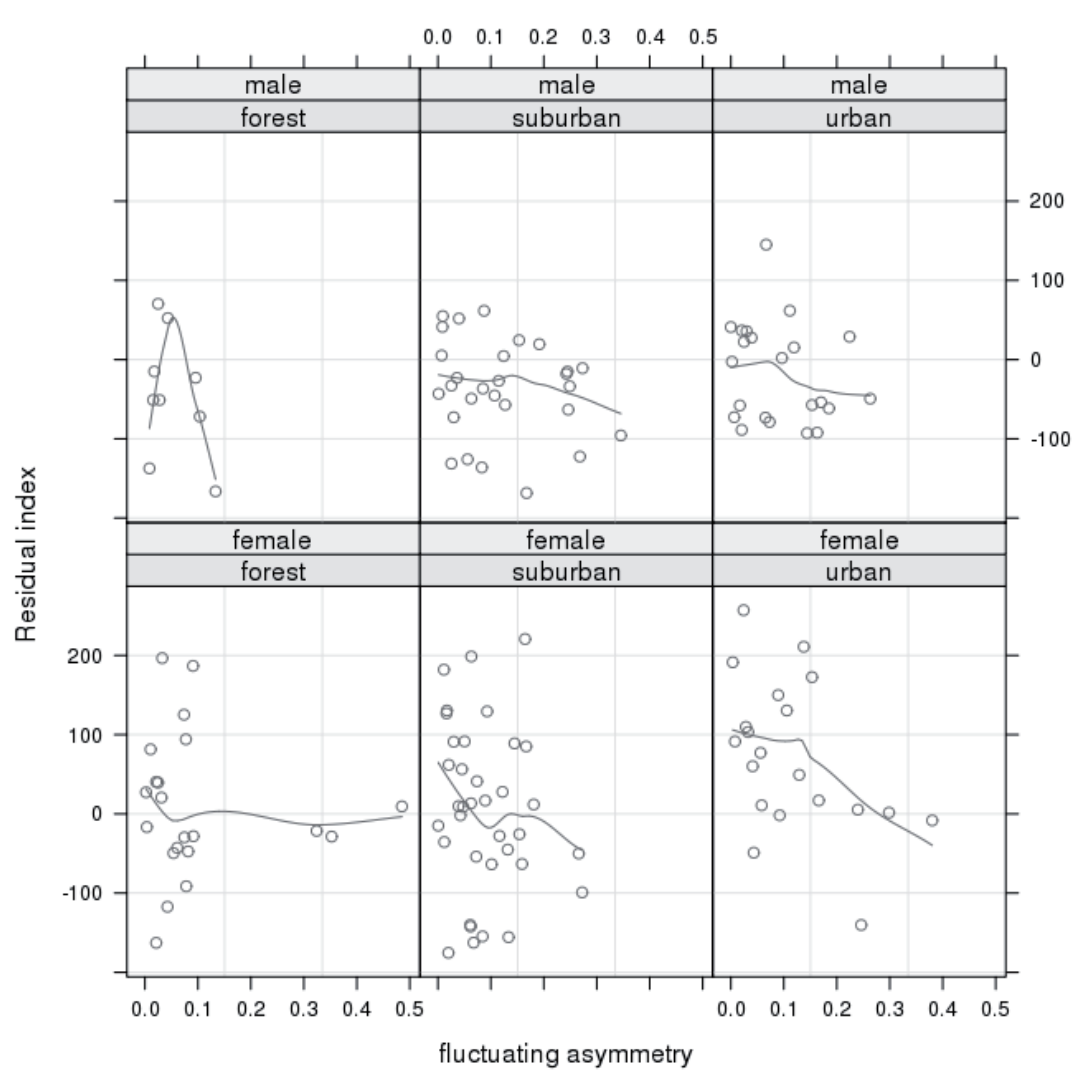




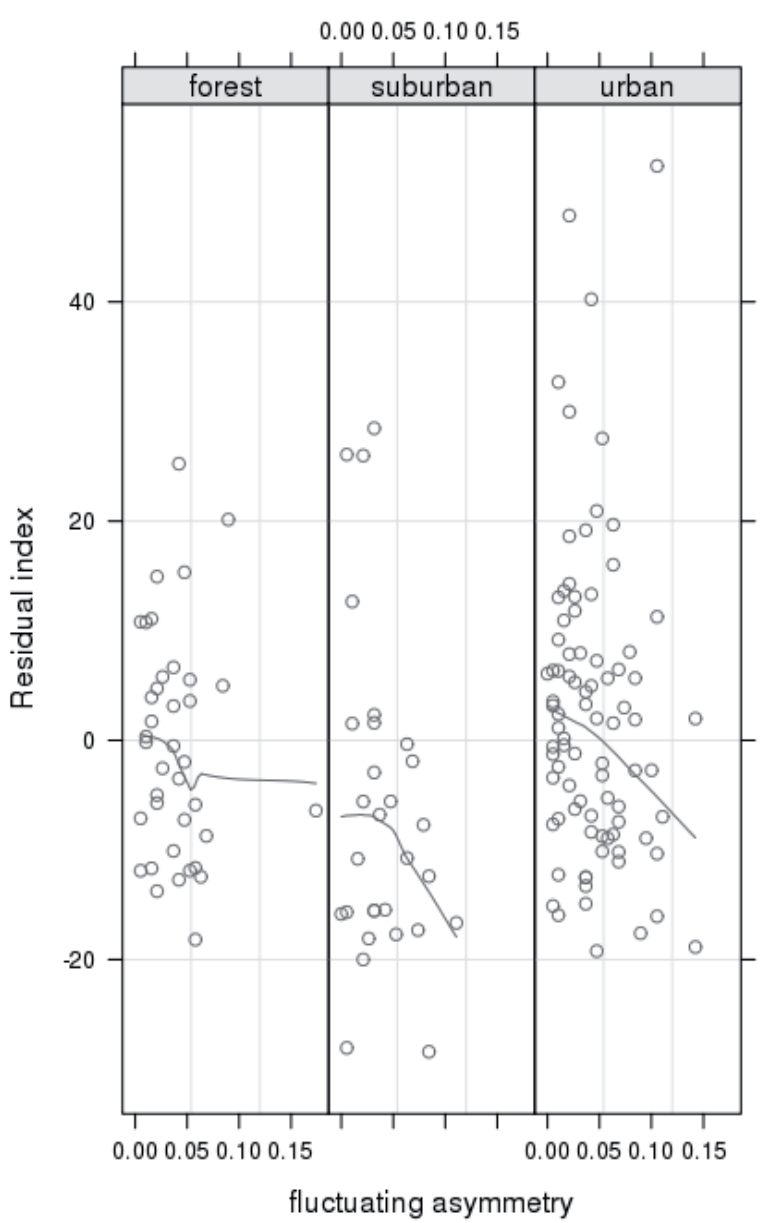

Figure 3. The relationship between the fluctuating asymmetry values and body condition in $N$. brevicollis along the urbanisation gradient in Sorø, Denmark, 2005. The line is the locally weighted regression between the two variables, with lambda $=1$, alpha $=0.9$.

\section{Discussion}

We hypothesised that the body condition of the individuals will be better in the less urbanised habitats (i.e., forest) than in forest fragments in urbanised areas. However, our results contradicted this: individuals of two common species, C. nemoralis and N. brevicollis showed better condition in the urban forest fragments than in the other habitats. The third one, the generalist predator $P$. melanarius did not show the best condition in the forest, either. While there are organisms where body condition is inferior in fragmented habitats, like treecreepers in Finnish forests (Suorsa et al. 2004), or salmanders in California (Karrakker et al., 2006), this is not universal. Wintering wood mice (Apodemus sylvaticus) in Spain have no worse body condition in forest fragments vs. continuous forest (Diaz et al. 1999), and several small mammal species in the Atlantic forest of Brazil have better body condition in fragmented than nonfragmented habitat (Puttker et al. 2008). Also, landscape management in Sweden did not influence body condition for wolf spiders as expected: the large, homogeneous fields were more favourable than organically managed, small fields (Öberg 2009 ). Therefore, the effect seems contextand species-dependent.

We found that the body condition of females in C. nemoralis and N. brevicollis was higher than that of males. This pattern was similar to those found for fluctuating asymmetry in females vs. males of $C$. nemoralis and P. melanarius (Elek et al. 2014): females had lower levels of fluctuating asymmetry than males. Females usually need more resources than males for reproduction, because they have to successfully form and lay fertile eggs (e.g., Uetz et al. 2002), and it is plausible to assume that inferior-quality females do not survive to reproduce (sensu lato Hendrickx et al. 2003).

Similarly, the high level of true asymmetry can be deleterious for the individuals and also can influence the larval-to-adult survival (Lens et al. 2002). Consequently, the surviving population could contain the individuals who survived these stress factors and are a robust subset of the original population, and whose asymmetry is now relatively unaffected by the current stressors (Floate and Fox 2000, Floate and Coghlin 2010). The wide scatter of condition in individuals with low degree of FA could reflect the variable nutritional conditions experienced. However, the generally low condition of individuals with high FA could indicate the lower quality of these habitats. This negative relationship was steeper in more urbanised habitats. This indicates that habitat quality was indeed lower in more urbanised habitats, and consequently, individuals with higher FA were able to cope less well than higher quality (less asymmetric) ones. We found a clear, consisent trend in our data, unlike Hendrickx et al. (2003).

\section{Conclusions}

Our results revealed that physiological condition may be a useful estimator of environmental conditions in urbanisation studies; and that the applied residual index for condition seems an appropriate analytical tool. However, the inconsistency of the species' responses indicated possible confounding effects (i.e., larval development, seasonal differences in sex ratio and condition). The applied loess regression model to relate condition and FA revealed that the fragmentation of forest patches during urbanisation could indeed create less favourable conditions for ground beetles. Based on the above results, we suggest to use the estimators in combination. Our results are consistent with the suggestion that physiological state indicators, especially those of body condition, could be a powerful early warning method of population decline during habitat change (Janin et al. 2011). Further, the complex interaction between tolerance limits, feeding conditions and stress levels during advancing urbanisation underlines the importance of using multiple criteria for assessing the impact of urbanisation on biodiversity.

Acknowledgements: We thank the Sorø Akademi Stilftelse for permission to work on their land, former Director Mr. J. Thomsen and Mr. A. Grube for their kind assistance, Dr. J. Jakobsen, Mrs. H-B. Christiensen, and Dr. H-P. Ravn for 
support and technical assistance, and Dr. Morten Pedersen (Dept. of Life Sciences and Chemistry, Roskilde University) for comments. This study was partially funded by the Danish International School for Biodiversity Studies (ISOBIS) (ZE), the Hungarian Scholarship Board (ZE), Aarhus University, Flakkebjerg Research Centre and the Domus Hungarica Foundation, Budapest, Hungary (GLL). This study was also partly supported by Hungarian Academy of Sciences (ZE) and Bolyai Research Grant (ZE, grant no.: BO/ 00045/11/8). This is publication no. 12 of the Danglobe Project. Author sequence follows the sequence by merit system. Author contributions: GLL, ZE: designed the study, all authors participated in field work; evaluation: ZE; writing: ZE, GLL.

\section{References}

Ball, S.L., B.A. Woodcock, S.G. Potts and M.S. Heard. 2015. Size matters: Body size determines functional responses of ground beetle interactions. Basic Appl. Ecol. 16:621-628.

Bolund, P. and S. Hunhammar. 1999. Ecosystem services in urban areas. Ecol. Econ. 29:293-301.

Cleveland, W. S. and S.J. Devlin. 1988. Locally weighted regression: an approach to regression analysis by local fitting. J. Am. Stat. Assoc. 83:596-610.

Cleveland, W. S., E. Grosse and W. M. Shyu. 1992. Local regression models. In: Chambers, J.M., Hastie, T.J. (eds.), Statistical Models in $S$. Wadsworth \& Brooks/Cole, Springer, New York.

Deepayan, S. 2008. Lattice: Multivariate Data Visualization with $R$. Springer, New York.

Diaz, M., T. Santos and J.L. Telleria. 1999. Effects of forest fragmentation on the winter body condition and population parameters of an habitat generalist, the wood mouse Apodemus sylvaticus: a test of hypotheses. Acta Oecol. 20:39-49.

Elek, Z., G.L. Lövei and M. Bátki. 2014. Fluctuating asymmetry in ground beetles (Carabidae) as an indication of the impact of urbanisation in Denmark. Community Ecol. 15:131-138.

Elek, Z. and G.L. Lövei. 2005. Ground beetle (Coleoptera, Carabidae) assemblages along an urbanisation gradient near Sorø, Zealand, Denmark. Entomologiske Meddelelser 73:115-121.

Elek, Z. and G.L. Lövei. 2007. Patterns of ground beetle (Coleoptera: Carabidae) assemblages along an urbanisation gradient in Denmark. Acta Oecol. 32:104-111.

Eversham, B.C., D.B. Roy, and M.G. Telfer. 1996. Urban industrial and other manmade sites as analogues of natural habitats for Carabidae. Ann. Zool. Fenn. 33:149-156.

Floate, K. D. and A.S. Fox. 2000. Flies under stress: a test of fluctuating asymmetry as a biomonitor of environmental quality. Ecol Appl. 10:1541-1550.

Floate, K. D. and P.C. Coghlin. 2010. No support for fluctuating asymmetry as a biomarker of chemical residues in livestock dung. Can. Entomol. 142:354-368.

Gaston, K. J., P.H. Warren, K. Thompson and R.M. Smith. 2005. Urban Domestic Gardens (IV): The Extent of the Resource and its Associated Features. Biodivers. Conserv. 14:3327-3349.

Gould, S. 1975. Allometry in primates, with emphasis on scaling and evolution of the brain. Contrib. Primatol. 5:244-292.

Hendrickx, F., J-P. Maelfait and L. Lens. 2003. Relationship between fluctuating asymmetry and fitness within and between stressed and unstressed populations of the wolf spider Pirata piraticus. J. Evolution. Biol. 16:1270-1279.
Hothorn, T., F. Bretz and P. Westfall. 2008. Simultaneous inference in general parametric models. Biometrical J. 50:346-363.

Hurrka, K. 1996. Carabidae of the Czech and Slovak Republics. Kabourek, Zlin, Czech Republic.

Jakob, E.M., S.D. Marshall and G.W. Uetz. 1996. Estimating fitness: a comparison of body condition indices. Oikos 77:61-67.

Janin A.U., A. Lena and J.P. Joly. 2011. Beyond occurrence: body condition and stress hormone as integrative indicators of habitat availability and fragmentation in the common toad. Biol. Conserv. 144:1008-1016.

Karraker, N. E. and H. Welsh. 2006. Long-term impacts of even-aged timber management on abundance and body condition of terrestrial amphibians in Northwestern California. Biol. Conserv. 131:132-140.

Knapp, M. and J. Knappová. 2013. Measurement of body condition in a common carabid beetle, Poecilus cupreus : A comparison of fresh weight, dry weight, and fat content. J. Insect Sci. 13:1-10.

Lagisz, M. 2008. Changes in morphology of the ground beetle Pterostichus oblongopunctatus F. (Coleoptera; Carabidae) from vicinities of a zinc and lead smelter. Environ. Toxicol Chem. 27:1744-1747.

Lens, L., S. Van Dongen and E. Matthysen. 2002. Fluctuating asymmetry as an early warning system in the critically endangered Taita thrush. Cons. Biol. 16:479-487.

Lindroth, C.H. 1985. The Carabidae (Coleoptera) of Fennoscandia and Denmark. Fauna Entomologica Scandinavica, Vol. 15, part 1. E.J. Brill, Leiden, The Netherlands.

Lindroth, C.H. 1986. The Carabidae (Coleoptera) of Fennoscandia and Denmark. Fauna Entomologica Scandinavica, Vol. 15, part 2. E.J. Brill, Leiden, The Netherlands.

Magura, T., B. Tóthmérész and T. Molnár. 2004. Changes in carabid beetle assemblages along an urbanisation gradient in the city of Debrecen, Hungary. Landscape Ecol. 19:747-759.

Magura, T., R. Horváth and B. Tóthmérész. 2010a. Effects of urbanization on ground-dwelling spiders in forest patches, in Hungary. Landscape Ecol. 25:621-629.

Magura, T., G.L. Lövei and B. Tóthmérész. 2010b. Does urbanization decrease diversity in ground beetle (Carabidae) assemblages? Global Ecol. Biogeogr. 19:16-26.

Marshall, S.D., E.M. Jakob and G.W. Uetz. 1999. Re-estimating fitness: can scaling issues confound condition indices? Oikos $87: 401-402$.

McIntyre, N.E., J. Rango, W.F. Fagan and S.H. Faeth. 2001. Ground arthropod community structure in a heterogeneous urban environment. Landscape Urban Plan. 52:257-274.

McKinney, M.L. 2001. Effects of human population, area, and time on non-native plant and fish diversity in the United States. Biol. Conserv. 100:243-252.

McKinney, M.L. and J.L. Lockwood. 1999. Biotic homogenization: a few winners replacing many losers in the next mass extinction. Trends Ecol. Evol. 14:450-453.

Mendiburu, F. 2010. agricolae: Statistical Procedures for Agricultural Research. R package version 1.0-9. http://CRAN.R-project.org/ package $=$ agricolae $($ accessed on $15 / 12 / 2017)$

Niemelä, J., J. Kotze, A., Ashworth, P. Brandmayr, K. Desender, T. New, L. Penev, M. Samways and J. Spence. 2000. The search for common anthropogenic impacts on biodiversity: a global network. J. Insect Conserv. 4:3-9.

Niemelä, J. and J. Kotze. 2009. Carabid beetle assemblages along urban to rural gradients: A review. Landscape Urban Plan. 92:65-71. 
Öberg, S. 2009. Influence of landscape structure and farming practice on body condition and fecundity of wolf spiders. Basic Appl. Ecol. 10:614-621.

Palmer, A. R. 1994. Fluctuating Asymmetry Analyses: A Primer, In: Markow, T. A. (ed.), Developmental Instability: Its Origins and Evolutionary Implications. Kluwer, Dordrecht. pp. 335-364.

Parsons, P.A. 1992. Fluctuating asymmetry: a biological monitor of environmental and genomic stress. Heredity 68:361-364.

Pickett, S.T.A., M.L. Cadenasso, J.M. Grove, C.H. Nilon, R.V. Pouyat, W.C. Zipperer and R. Costanza. 2001. Urban ecological systems: linking terrestrial ecological, physical, and socioeconomic components of metropolitan areas. Annu. Rev. Ecol. S. 32:127-157.

Pickett, S.T.A., M.L. Cadenasso, J.M. Grove, C.G. Boone, P.M Groffman, E. Irwin, S.S. Kaushal, V. Marshall, B.P. McGrath, C.H. Nilon, R.V. Pouyat, K. Szlávecz, A. Troy and P. Warren. 2010. Urban ecological systems: Scientific foundations and a decade of progress. J. Environ. Manage. 92:331-362.

Puttker, T., Y. Meyer-Lucht and S. Sommer. 2008. Effects of fragmentation on parasite burden (nematodes) of generalist and specialist small mammal species in secondary forest fragments of the coastal Atlantic Forest, Brazil. Ecol. Res. 23:207-215.

Rasband, W. 2003. ImageJ Image Processing and Analysis in Java. National Institutes of Health, USA, <http://rsb.info.nih.gov/ij/ (accessed on 15/12/2017).
R Development Core Team. 2010. R: A Language and Environment for Statistical Computing. R Foundation for Statistical Computing, Vienna, Austria. ISBN 3-900051-07-0, http://www.R-project.org.

Sapia, M., G.L. Lövei and Z. Elek. 2006. Effects of varying sampling effort on the observed diversity of carabid (Coleoptera: Carabidae) assemblages in the Danglobe Project, Denmark. Entomol. Fennica 17:345-350.

Suorsa, P., H. Helle, V Koivunen, E. Huhta, A. Nikula and H. Hakkarainen. 2004. Effects of forest patch size on physiological stress and immunocompetence in an area-sensitive passerine, the Eurasian treecreeper (Certhia familiaris): an experiment. Proc. Roy. Soc. B-Biol. Sci. 271:435-440.

Uetz, G.W., R. Papke and B. Kilinc. 2002. Influence of feeding regime on body size, body condition and a male secondary sexual character in Schizocosa ocreata wolf spiders (Araneae, Lycosidae): condition-dependence in a visual signaling trait. $J$. Arachnol. 30:461-469.

United Nations 2006. World Urbanisation Prospects: The 2005 Revision. Population Division, Dept Economic and Social Affairs. United Nations, New York.

Vilisics, F., Z. Elek, G.L. Lövei and E. Hornung. 2007. Composition of terrestrial isopod assemblages along an urbanisation gradient in Denmark. Pedobiologia 51:45-53.

Received October 20, 2017

Revised December 6, 2017 Accepted December 18, 2017 